\title{
ยกி \\ กी \\ A Gestão Pública do Sistema da Universidade Aberta do Brasil: Estudo de Caso no Polo de Apoio Presencial em Resende
}

\begin{abstract}
Marcos Antonio Gomes Xavier ${ }^{1}$
${ }^{1}$ Tutor Presencial, Centro de Educação Superior a Distância do Estado do Rio de Janeiro/Universidade Federal Fluminense. Travessa Antimio, 31, Bento Ribeiro - Rio de Janeiro-RJ - Brasil. magxita@yahoo.com.br
\end{abstract}

\section{Resumo}

Este artigo trata da Gestão da Educação a Distância pelas instituições de ensino superior, parceiras da Universidade Aberta do Brasil, descrevendo fatores estruturais e organizacionais essenciais para a gestão de qualidade. Através do estudo de caso, com desenvolvimento de pesquisa exploratória, no Polo de Apoio Presencial do Município de Resende, no Estado do Rio de Janeiro, foi possível observar que o polo é elemento-chave no sistema para que propicie ensino de qualidade; para tanto, enfatiza-se a importância do papel do gestor do polo nesse contexto.

Palavras-chave: Gestão; Educação a distância; Polo de apoio presencial. 


\title{
The Public Management of Open University of Brazil: A Case Study in Resende Learning Support Center
}

\begin{abstract}
This article reports how higher education institutions, partners of the Open University of Brazill, deals with Distance Education Management, by describing structural and organizational factors, essential for a quality management. Through the case study, with exploratory development, he Learning Support Center in the municipality of Resende in the state of Rio de Janeiro, we observed that the Polo is a key element in the system, that provides quality education, therefore, it is emphasized the important role of the manager at this Learning Center in this context.
\end{abstract}

Keywords: Management; Distance Education; Learning Support Center. 


\section{Introdução}

O Brasil, país de dimensões continentais, tem investido na implementação da Educação a Distância (EaD), conforme consta na Figura 1, por ser um projeto viável e capaz de solucionar, ou pelo menos minimizar, a desproporção que existe atualmente entre a elevada demanda - quantidade de pessoas para serem educadas, e a baixa oferta - quantidade de instituições de ensino (infraestrutura física) disponível e o contingente de educadores capacitados, por região.

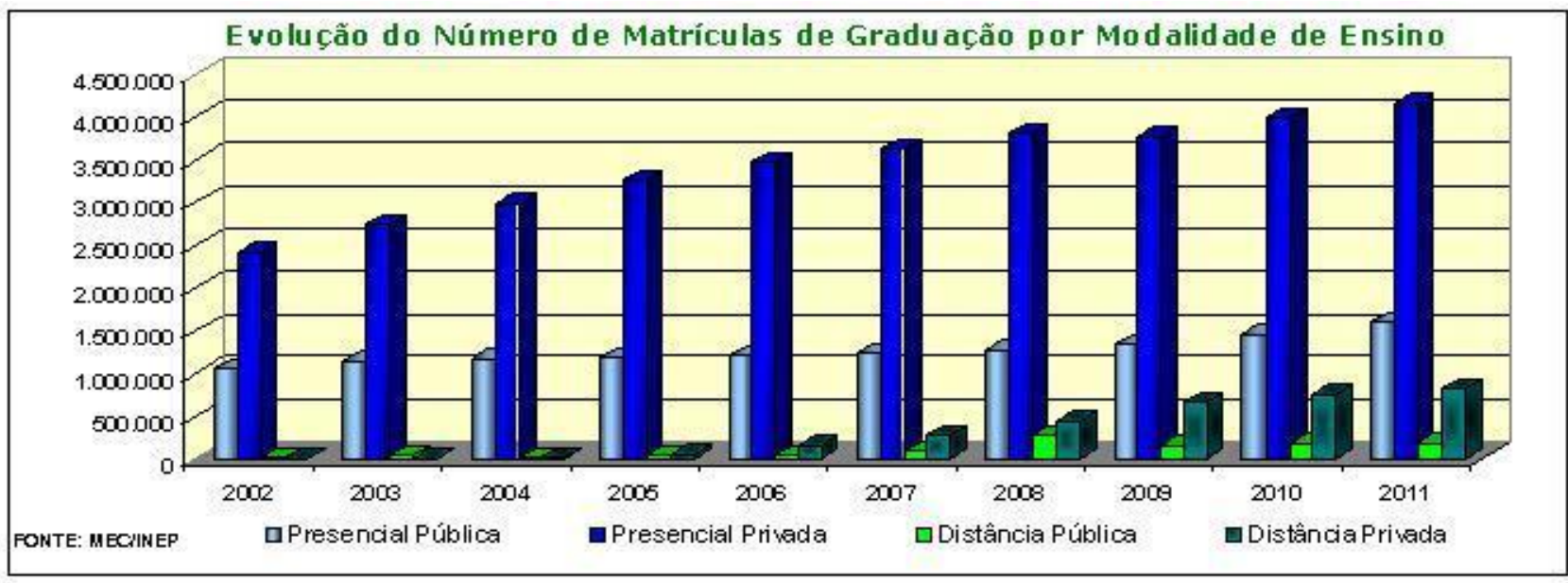

Figura 1 - Evolução do Número de Matrículas de Graduação por Modalidade de Ensino.

Fonte: MEC / INEP

A fim de contribuir para o debate a respeito dos aspectos da gestão pública dos cursos na modalidade a distância, são apresentadas algumas das novas posturas estratégicas necessárias para o sucesso da EaD, com o foco sobre questões relativas a implementação e o desenvolvimento de cursos na modalidade, visualizando seus mecanismos primordiais e as competências do gestor em EaD - o coordenador de polo, que requer "o domínio e emprego das técnicas relacionadas com: Gestão estratégica; Gestão de projetos; Gestão da infraestrutura; Gestão de equipe e Gestão de processos" (Ribas, Moreira \& Catapan, 2011) para exercer sua função perante a organização e administração do polo de apoio presencial (PAP). Segundo Ribas, Moreira e Catapan (2011), o polo de apoio presencial "é um elemento fundamental na estrutura da educação a distância, constituindo-se numa extensão operacional da instituição de ensino superior na cidade do estudante ou mais próxima dele". 
Com base, principalmente, nas dificuldades da implementação e gestão da $\mathrm{EaD}$, em PAP do Sistema da Universidade Aberta do Brasil (UAB), o texto estabelece algumas especificidades dos sistemas desta modalidade, buscando compreender suas particularidades, identificando e analisando suas principais estruturas de adoção e manutenção. Como afirmam Mill et al. (2010), a "criação de um sistema de gestão diferenciado $[\ldots]$ torna-se um desafio aos atuais ou futuros gestores de programas de EaD". Assim, busca-se o aproveitamento dessas estruturas e a sistematização de teorias já consolidadas para essa modalidade de educação, contribuindo para o constante desenvolvimento da EaD.

\subsection{Justificativa}

Diante do fato de que o planejamento adequado da gestão da EaD é fundamental para o seu sucesso, pois, segundo Paula, Ferneda e Filho (2004), ao "planejar um curso a distância, é importante que o projeto pedagógico esteja adequado à metodologia do curso e integrado ao ferramental tecnológico disponível"; sobre esse contexto, este trabalho busca dilatar novos horizontes sobre os projetos existentes de gestão, envolvendo o planejamento e a aplicação de ações que mobilizariam as mudanças necessárias na busca de soluções para os problemas existentes na gestão pública de cursos a distância em PAP das instituições públicas de ensino superior (IPES), do Sistema da UAB. Segundo Ribas, Moreira e Catapan (2011) os PAPs, distribuídos geograficamente, possibilitam que uma quantidade enorme de pessoas estude, se atualize, mesmo estando distante das IPES, democratizando o saber.

O objetivo dos polos é oferecer o espaço físico de apoio presencial aos alunos da sua região, mantendo as instalações físicas necessárias para atender aos alunos em questões tecnológicas, de laboratório, de biblioteca, entre outras (UAB/Capes, 2013).

Nesse cenário, é importante ressaltar que, por mais que exista uma estrutura básica formalmente definida em um PAP para atender às demandas de um curso na modalidade EaD, existe a possibilidade de cada edificação apresentar condições de infraestrutura diferentes, abrigando diversos e diferentes cursos, em que "a aquisição de alguns equipamentos depende dos cursos a serem oferecidos e de orientações das IES que oferecem esses cursos no polo" (UAB/Capes, 2013). 
Apesar dos riscos envolvidos na abordagem de um tema tão complexo, espera-se contribuir com a análise do contexto próprio da gestão pública da EaD, a partir de suas estruturas principais, verificando e promovendo as alterações necessárias para a ampliação da modalidade EaD.

\subsection{Objetivos}

O objetivo geral é compreender o ambiente da gestão do PAP, identificar as características de uma gestão que melhor contribua para o desenvolvimento da modalidade EaD.

Os objetivos específicos são: relacionar os elementos essenciais para a implementação de curso na modalidade EaD em instituições públicas de ensino superior; identificar os diversos fatores estruturais e organizacionais essenciais existentes na gestão de qualidade na EaD do PAP Resende.

\subsection{Metodologia}

O processo metodológico a ser seguido é o estudo de caso "com coordenador de polo de apoio presencial sobre a gestão da EaD". O foco desta etapa do trabalho consiste na identificação da estrutura e do funcionamento do PAP, em especial do Sistema UAB; na busca de compreender a gestão do PAP, identificando o clima organizacional, a gestão de pessoas, as estruturas e procedimentos para obter uma gestão de qualidade.

Nesse contexto, a abordagem metodológica dessa etapa do trabalho é do tipo de análise de um estudo de caso $^{1}$, com pesquisa exploratória descritiva ${ }^{2}$, de caráter qualitativo $^{3}$. Na etapa da coleta de dados junto à coordenadora - Alice Batista de Souza Brandão, do Polo Resende, localizado no Estado do Rio de Janeiro, a técnica adotada é a entrevista ${ }^{4}$ semiestruturada, pois possibilita, durante os encontros, incluir novos questionamentos sem perder os objetivos da investigação.

O roteiro da entrevista utilizado foi elaborado tendo como referência os aspectos apresentados nos Referenciais de Qualidade para a Educação Superior a Distância e outros documentos que tratam do assunto, possibilitando assim uma análise 
comparativa da situação real da gestão pública da EaD e a descrita como ideal pelos documentos oficiais.

Em todos os encontros, as entrevistas são registradas, gravadas em arquivos de áudio e de imagens, contendo a aplicação das perguntas, ou seja, do questionário ${ }^{5}$, e as respostas dadas pela coordenadora. Por conseguinte, o responsável deste estudo realizou a análise de conteúdo (três fases: pré-análise, análise do material e tratamento de resultados) nos documentos disponibilizados pela coordenação do PAP e nas respostas.

Na etapa de análise das entrevistas, as informações foram organizadas segundo sua relação com as questões apresentadas. Assim, a pesquisa estabelece inferências sobre a estrutura e organização do PAP, a importância do gestor de PAP, entre outros.

\subsection{Fundamentação teórica}

No Brasil, o Ministério da Educação (MEC), para suas políticas públicas para EaD, agiu com secretaria própria até 2011 (Secretaria de Educação a Distância - SEED); atualmente, nas secretarias convencionais (Secretaria de Educação Básica ou de Ensino Superior), responsável em democratizar, dar acesso à informação e à educação, dando aos excluídos dos grandes centros a oportunidade de uma educação de qualidade. Esse órgão regulamenta e propõe indicadores de qualidade para $\mathrm{EaD}$, bem como orienta as instituições e as comissões de especialistas para fins de projetos e ações que contemplem a modalidade a distância.

Com a Lei de Diretrizes e Bases da Educação - Lei 9.394, de 20 de dezembro de 1996 -, a EaD tem respaldo legal; os Decretos seguintes regulamentam os aspectos variados que tangem à modalidade de EaD, tal como ações contínuas de políticas públicas que fomentam e dinamizam a disseminação de PAP e a implementação de cursos de graduação e especialização, entre outros.

Nos dias atuais, observa-se um campo promissor para a EaD, pois, além "do baixo acesso à Educação Superior no Brasil devido à oferta limitada de vagas nas IPES", conforme afirma Santos (2012), existe também grande demanda por educação continuada, capacitação e atualização profissional, que encontra nessa modalidade 
grandes possibilidades de implementação, sem necessitar tirar os profissionais de seu trabalho.

A EaD tem como desafio superar as distâncias, a sua relação espaço físico/geográfico e temporal entre professor e aluno, mas apoia-se fundamentalmente nos meios de comunicação e na tecnologia para construir a aprendizagem de forma individual e coletiva, ao mesmo tempo que socializa e democratiza a educação, amplia as possibilidades do saber, criando e potencializando competências de uma sociedade norteada pela informação.

A gestão de cursos na modalidade EaD deve estar integrada aos demais processos da instituição, ou seja, é de fundamental importância que o estudante de um curso a distância tenha as mesmas condições e suporte que o de um curso presencial, e o sistema acadêmico deve priorizar isso, no sentido de oferecer ao estudante geograficamente distante o acesso aos mesmos serviços disponíveis ao do ensino tradicional, como: matrícula, inscrições, requisições, informações institucionais, secretaria, tesouraria etc.

Numa primeira etapa, a partir do conjunto sequencial da gestão da EaD, é preciso estabelecer os papéis de todos os envolvidos e os procedimentos que eles devem desempenhar para que os objetivos definidos sejam alcançados. "O detalhamento das ações deve priorizar o grau de importância, estratégias, rotinas e atividades acadêmicas e administrativas [...]. A capacitação de todos os atores deve ser considerada objetivo estratégico e deve ter como princípio a qualidade do ensino" (Garbin; Dainese, 2010).

O modelo da EaD exige gerenciamento adequado para que os objetivos do curso sejam atingidos. Assim, é preciso que a equipe domine específicas técnicas de gestão ${ }^{6}$, como a gestão estratégica, de projetos ${ }^{7}$, da infraestrutura, de equipe e de processos, tornando possível a abrangência das particularidades da EaD.

Nesse contexto, a gestão do curso é um fator muito importante, que requer do gestor uma visão sistêmica dos processos para desempenhar melhor suas funções, pois é ele o responsável pela gestão da equipe, do espaço físico, da organização, da administração e promoção da EaD em âmbito local.

Dessa forma, as instalações físicas, a infraestrutura tecnológica e de recursos humanos mostram-se essenciais para contribuir na qualidade da EaD. Então, garantir efetivamente o pleno desenvolvimento das atividades dos cursos a distância e oferecer 
condições e serviços adequados e suficientes para atender aos atores envolvidos em suas expectativas, demandas e necessidades requerem um espaço bem projetado, quando surge a proposta do PAP ${ }^{8}$.

O PAP constitui o "braço operacional" da instituição de ensino superior na cidade do estudante (ou na mais próxima dele); segundo Ribas, Moreira e Catapan (2011), torna-se um elemento primordial para a EaD e para a sua viabilização, pois visa ao acompanhamento, à orientação dos cursistas e a seu desenvolvimento, disponibilizando e favorecendo as práticas laboratoriais.

A questão da gestão do PAP está diretamente ligada à sua estrutura, formalmente definida e disciplinada pelo Sistema UAB, instituído pelo Decreto no 5.800/06, com a finalidade de "expandir e interiorizar a oferta de cursos e programas de Educação Superior no País, por meio do desenvolvimento de programas e de cursos na modalidade de educação a distância". O Sistema UAB, segundo o FNDE (2009),

cumprirá suas finalidades e objetivos socioeducacionais em regime de colaboração da União com entes federativos, obedecendo às seguintes diretrizes:

I - oferecer, prioritariamente, cursos de nível superior de formação inicial e continuada para professores da Educação Básica;

II - oferecer cursos de nível superior para capacitação de dirigentes, gestores e trabalhadores em Educação Básica dos estados, do Distrito Federal e dos municípios;

III - oferecer cursos de nível superior nas diferentes áreas do conhecimento;

IV - ampliar o acesso à Educação Superior pública;

$\mathrm{V}$ - reduzir as desigualdades de oferta de Ensino Superior entre as diferentes regiões do País;

VI - estabelecer amplo sistema nacional de Educação Superior a distância; e

VII - fomentar o desenvolvimento institucional para a modalidade de educação a distância, bem como a pesquisa em metodologias inovadoras de Ensino Superior apoiadas em tecnologias de informação e comunicação (FNDE, 2009).

O êxito do sistema, indubitavelmente, depende de seu bom funcionamento, desde que garanta uma estrutura administrativa e pedagógica adequada para atendimento e, fundamentalmente, gestores capacitados.

O gestor ou administrador de PAP, no caso da EaD, é o coordenador de PAP. Conforme a Resolução CD/FNDE no 26, de 5 de junho de 2009, que estabelece 
orientações e diretrizes para pagamento de bolsas de estudo e de pesquisa a participantes no âmbito do Sistema UAB, o coordenador de PAP é um "professor da rede pública, graduado e com, no mínimo, 3 anos em magistério na Educação Básica ou Superior", responsável pela coordenação do PAP. Dentre as funções do coordenador listadas no sitio da UAB, destaca-se: "articular-se com o mantenedor do polo com o objetivo de prover as necessidades materiais, de pessoal e de ampliação do polo" (UAB/Capes, 2013).

Assim, como de qualquer gestor, espera-se do coordenador de PAP que exerça suas funções de acordo com o modelo de gestão PEAC: Planejamento; Execução; Avaliação e Controle, que são essenciais para que os objetivos propostos pela organização sejam interpretados e transformados em ação, com o intuito de atingir os objetivos. Bergue (2012b) relata que "a existência das organizações está relacionada à distribuição e execução de tarefas, e que isso se dá por intermédio das pessoas, que por sua vez não se dissociam de suas escalas sociais de valores éticos" e que a "cultura é algo que permeia a estrutura, os processos e as pessoas de uma organização, interferindo de forma determinante no seu desempenho".

Nesse cenário, torna-se importante a gestão estratégica, como a capacitação dos agentes da organização em dirigir seus rumos de forma a permitir que as decisões administrativas e operacionais estejam de acordo com as decisões estratégicas. Na área da Administração para a gestão pública o nível da gestão estratégica tem como objeto as políticas públicas, segundo Malmegrin (2012b). A partir dessas conceituações podese perceber que a capacitação do coordenador de PAP tem pressupostos que visam a alcançar uniformidade de ações e resultados no PAP.

Dessa forma, a gestão de um PAP deve seguir o que preceitua a gestão estratégica, bem como será necessário um planejamento obedecendo às regras básicas contidas nos Referenciais de Qualidade para Educação Superior a Distância do MECSEED; sendo assim, um coordenador de PAP deverá ter atributos e competências específicas de gestão: visão estratégica; projetos; infraestrutura; equipe e processos, pois ele é o meio de intercâmbio entre diversos atores - cursista; sociedade; MEC; IES; órgão mantenedor e equipe multidisciplinar - envolvidos no contexto desse profissional.

O desafio do coordenador de PAP está em zelar para o bom funcionamento e cumprimento do que se destina o "braço" da IPES, ou seja, o gestor tem papel importantíssimo na institucionalização ${ }^{9}$ do PAP. 


\section{Resultados e discussão}

No Brasil, atualmente, segundo a Secretaria de Educação a Distância (SEED) do Ministério da Educação (MEC), existem em andamento nas IES diferentes modelos de oferta de cursos a distância. Contudo, as discussões e resultados apresentados a seguir são referentes ao estudo da gestão da EaD com ênfase na organização de sistema de EaD que integraram o PAP no conjunto de instalações, mais especificamente na pesquisa e análise do Polo Resende (RES), que faz parte do conjunto de 35 instalações dos Sistemas UAB sediadas em municípios espalhados geograficamente no Estado do Rio de Janeiro.

Já se passaram aproximadamente 5 anos da data de inauguração do PAP da UAB Resende, até o $2^{\circ}$ semestre letivo de 2013. No Quadro 1 são apresentados os principais eventos ocorridos durante o período de fevereiro de 2006 a dezembro de 2013. Alguns desses eventos requerem atenção, pois apresentam dados importantes sobre a evolução institucional do Polo Resende. São eles:

- A vinculação do polo RES com o Sistema Cederj, que possibilitou a oferta de cursos de graduação;

- Considerando que o Consórcio Cederj possui em seu portfólio de cursos na modalidade semipresencial ${ }^{10} 13$ títulos, conforme consta em seu sitio, é possível afirmar que o Polo RES oferta atualmente $70 \%$ desses cursos;

- A participação da atual coordenadora do Polo RES, desde a confecção da proposta do projeto de implantação do PAP.

Sobre este último item da lista de eventos, a entrevistada relatou ainda alguns detalhes sobre o relatório da "Caracterização do Município de Resende", contendo os principais índices sobre a Educação em Resende em 2005, que são listados no Quadro 2, e a sua defesa para o projeto do PAP apresentada ao Secretário Municipal de Educação da Prefeitura Municipal de Resende (PMR), que se sustentava na questão sobre a parte do custeio da implantação de infraestrutura do PAP/UAB pela PMR, que equivalia a um terço do custo total para a graduação dos professores da PMR em IES da rede privada, que, diga-se de passagem, é um direito adquirido desse agente público. 


\section{Quadro1 - Linha do Tempo do Polo Resende}

\begin{tabular}{|c|c|}
\hline Resende & Ano \\
\hline $\begin{array}{l}\text { Submissão do Projeto de implantação do PAP em Resende, conforme Edital } \\
\text { 01/SEED/MEC - Chamada Pública. }\end{array}$ & $02 / 2006$ \\
\hline $\begin{array}{l}\text { Aprovação do projeto de implantação do PAP e assinatura do termo de } \\
\text { cooperação técnica entre União e Prefeitura Municipal de Resende, em } \\
\text { Brasília. }\end{array}$ & $05 / 2006$ \\
\hline $\begin{array}{l}\text { Início da implantação do PAP/UAB em Resende, no } 3^{\circ} \text { andar do prédio da } \\
\text { Secretaria Municipal de Educação (PMR). }\end{array}$ & $06 / 2006$ \\
\hline $\begin{array}{l}\text { Chegada dos equipamentos (50 unidades de computadores doados pelo } \\
\text { MEC). Organização de dois laboratórios de informática. }\end{array}$ & $03 / 2007$ \\
\hline $\begin{array}{l}\text { Inauguração do PAP UAB. Oferta do } 1^{\circ} \text { curso de pós-graduação: Design } \\
\text { Instrucional para EaD Virtual, pela Unifei. }\end{array}$ & $09 / 2007$ \\
\hline $\begin{array}{l}\text { Inauguração PAP Cederj no Campus UERJ - Polo Resende - FAT. Oferta de } \\
2 \text { (dois) cursos. Licenciaturas: Ciências Biológicas e Pedagogia. }\end{array}$ & 2007 \\
\hline $\begin{array}{l}\text { PAP UAB/Cederj, denominado Polo Resende-Centro. Oferta de } 2 \text { cursos: } \\
\text { bacharelado em Administração e Licenciatura em Matemática. }\end{array}$ & 2008 \\
\hline $\begin{array}{l}\text { A Direção Central do Cederj, em conjunto com o Poder Público Municipal, } \\
\text { fazem a unificação dos polos: Resende FAT e Resende-Centro, tornando } \\
\text { apenas um Polo em Resende, a ser denominado Polo Resende UAB/Cederj. }\end{array}$ & 2012 \\
\hline $\begin{array}{l}\text { Oferta atualmente } 18 \text { cursos. } \\
\text { Licenciaturas (Cederj): Matemática, Física, Turismo, Geografia, História, } \\
\text { Pedagogia e Biologia. Bacharelado (Cederj): Administração Pública e } \\
\text { Administração. Pós-graduação: UniRio - Gestão Pública Municipal, Educação } \\
\text { Especial e Gestão em Saúde. Unifei - Design Instrucional para EaD Virtual e } \\
\text { Gestão de Pessoas e Projetos Sociais. UFF-NTEM. Sequencial e } \\
\text { Aperfeiçoamento: UFF - Educação Étnico-Racial e Empreendedorismo e } \\
\text { Inovação. Fiocruz - Ativação de processos e mudanças na formação, } \\
\text { Facilitadores de educação permanente em saúde, Gestão de projetos de } \\
\text { investimentos em saúde e Gestão em saúde. }\end{array}$ & $12 / 2013$ \\
\hline
\end{tabular}


Quadro 2 - Índices da educação em Resende - 2005

\begin{tabular}{|l|l|}
\hline \multicolumn{1}{|c|}{ Itens } & \multicolumn{1}{c|}{ Resultados } \\
\hline Atendimentos das Creches & $11 \%$ (Meta era de $30 \%$ ) \\
\hline Ensino Fundamental & $68 \%$ produção \\
\hline Ensino Médio & $12 \%$ produção \\
\hline Professores sem curso de nível superior & $70 \%$ \\
\hline
\end{tabular}

Conforme as informações extraídas do sitio do Cederj sobre a oferta de vagas por curso e polo para o vestibular de 2013.2, observa-se que em média 300 alunos calouros ingressam no Polo RES, reforçando assim a necessidade de verificar as condições das instalações físicas, da infraestrutura tecnológica e dos recursos humanos, pois são bases essenciais que contribuem para melhorar a qualidade da educação.

Confrontando a proposta de estrutura mínima (incluindo mobiliários e equipamentos e recursos humanos) em um PAP apresentada no sitio da UAB, que visam a nortear, oferecer uma base de estimativa para os investimentos por parte dos mantenedores (estados e/ou municípios) e as imagens do Relatório de Fotos do Polo RES, nota-se que basicamente todos os requisitos para a estrutura mínima foram atendidos. Sobre o tema, a coordenadora do Polo ressalta que o mais importante para a estrutura do PAP está numa equipe de "bons" tutores e uma secretaria com profissionais qualificados para atendimento ao público.

No entanto, a coordenadora de Polo RES apresentou relato de pelo menos um cenário problemático, que envolve a questão do Acordo de Cooperação Técnica ${ }^{11}$ entre as três esferas administrativas, em que cabe ao mantenedor prover e manter a infraestrutura e ceder e manter os funcionários (técnicos e administrativos). No Polo RES, o quadro atual possui 18 funcionários cedidos pela PMR com cargas horárias diferenciadas, entre 5 e 40 horas, o que vem ocasionar problemas na gestão administrativa, pois a carga horária é desigual. O polo funciona para atender as questões acadêmicas das $13 \mathrm{~h}$ às $22 \mathrm{~h}$, de terça-feira a sexta-feira, praticamente o dia inteiro aos sábados e aos domingos também, quando há atividades, como a aplicação das avaliações presenciais (AP) dos cursos do Cederj. Durante os dias úteis, no horário da manhã, que se inicia às $8 \mathrm{~h}$, o polo requer a presença de funcionários, pois tem expediente para atender o correio, o malote que chega, o público da terceira idade (que usa o laboratório 
de informática para inclusão digital etc.). Além desse cenário, existe o fato de que pessoas adoecem, necessitam faltar por motivos particulares, ou seja, o quadro funcional cedido pelo parceiro, no caso a PMR, necessita de regulamentação, pois não atende à demanda atual.

Os pré-requisitos para ser um coordenador de polo, identificados no sítio da UAB, são competências básicas para exercer as suas atividades do cotidiano da função. Segundo a entrevistada, os candidatos indicados pelo mantenedor local do PAP (prefeitura ou estado) para o cargo de coordenador, devem minimamente apresentar as seguintes qualificações: ser servidor público; possuir graduação superior - se tiver mestrado, melhor; ter conhecimento sobre Educação Básica e possuir conexão com os gestores mantenedores do PAP. Cabe ressaltar que, ainda segundo a entrevistada, no início da implantação de um PAP é de suma importância a terceira competência.

Um ponto relevante relatado pela entrevistada quanto às atribuições que cabem à função do gestor do PAP está nas ações de "dividir tarefas"12 entre os colaboradores da sua equipe, do ato de supervisionar, acompanhar os resultados, fazer a ligação entre os funcionários e ajudar a equipe nos momentos de grandes demandas num determinado serviço ou tarefa. Para Alice Brandão, a gestão do polo se torna eficiente e eficaz ${ }^{13}$ quando se tem um "plano de gestão" que apresente minimamente o organograma ${ }^{14}$ do polo, fluxograma dos macroprocessos e a relação das atividades por cargo/função. O plano de gestão do Polo Resende, segundo a sua coordenação, está dividido em departamentos ${ }^{15}$ : Patrimônio e manutenção, Secretaria, Biblioteca, Material didático, Pessoas, Tecnologia e Tutoria; cada um possui um responsável. A principal vantagem de adotar a estratégia de divisão, criando setores por processos, está em "identificar áreas de trabalho em que estão concentrados processos específicos ou atividades próprias de um macroprocesso organizacional" (Bergue, 2012a) e em facilitar o gerenciamento dos problemas exclusivamente daquele contexto em uma única intervenção, por meio de encontro semanal pontual com o responsável de cada setor.

Para a Coordenadora entrevistada, entre os desafios enfrentados pelos coordenadores de PAP no seu cotidiano, o setor mais crítico a ser gerenciado está o patrimônio, por dois motivos:

- Pela falta de recursos de segurança, principalmente os tecnológicos, tal como um sistema que armazene e transmita as imagens de ambientes como laboratórios de 
informática, de Física ou de Biologia, onde se concentram equipamentos valiosos, pertencentes aos mantenedores do polo, facílimos de serem extraviados ou danificados.

- Requer cuidados com o controle de materiais que possuem valores monetários expressivos, cedidos pelas três esferas de governo, além de doações. A identificação do material, mediante o uso de placa de patrimônio, se torna um procedimento importantíssimo na gestão, pois, além de facilitar a identificação visual das características e origem do material, possibilita tanto ao coordenador quanto ao mantenedor realizar controles e auditorias, por meio de inventários periódicos, como o anual realizado pelo Cederj.

A função de coordenador de PAP requer conhecimentos em diversas disciplinas para exercer com competência a gestão da EaD. A coordenadora do Polo RES destacou os seguintes pontos sobre o tema, em relação à UAB:

- Realização de um encontro anual com todos os seus coordenadores de polo;

- Disponibilização de recursos tecnológicos virtuais pela internet: $\operatorname{ATUAB}^{16} \mathrm{e}$ SISUAB ${ }^{17}$.

O desenvolvimento institucional, para Alice Brandão, é prioridade em sua gestão do PAP. Para tal, uma das ações está em agendar a cada mês um encontro para tratar desse tema, do qual participam o coordenador de Polo Resende UAB/Cederj; o secretário Municipal de Educação (PMR); o presidente da Câmara de Vereadores; um representante do prefeito (PMR) e o articulador de Desenvolvimento Institucional (funcionário da PMR cedido ao polo), o professor Haroldo, que recentemente também passou a fazer quadro dos tutores presenciais do polo. Um dos resultados obtidos desses encontros está no mapeamento dos cursos necessários para atender às demandas da região e analisar a situação do momento do polo, no que tange aos recursos de infraestrutura, pessoal e outras rubricas. Em outras palavras, conhecer o cenário do polo no que se refere principalmente a identificar se o polo comporta receber novos cursos, se o polo requer novos ou mais recursos. Em seguida, sinalizar formalmente para os parceiros do polo, em especial ao Cederj e a Capes $^{18}$, a necessidade atual do Polo Resende, que já indica a necessidade de ofertar novos cursos de Geografia e Sistema de Informação. 


\section{Considerações finais}

A oportunidade de analisar a comparação da situação real e a descrita como ideal pelos documentos oficiais, por meio da experiência de entrevistar coordenador de polo do Sistema UAB, em Resende, durante o desenvolvimento e aperfeiçoamento do projeto de pesquisa sobre a Gestão Pública em Polo de Apoio Presencial do Sistema da UAB, que estabelece inferências sobre a estrutura, a organização e o gestor do PAP, configurouse como única ao autor desta pesquisa.

Este estudo reafirma que, dentro da EaD, a organização da divisão de funções entre os profissionais que integram a equipe multidisciplinar se torna fator primordial para realização de um trabalho de qualidade. No entanto, o sucesso só é alcançado com a interação das partes envolvidas. Nesse cenário, o coordenador de PAP se torna o agente condutor, o líder ${ }^{19}$, o elo de intervenção e mediação dentro da equipe; suas ações devem ser estruturalmente planejadas, explorando todo o potencial das gestões e das tecnologias comunicacionais e informacionais, viabilizando assim estratégias que otimizem os processos da EaD.

Todos os relatos apresentados pela coordenadora do Polo Resende permitiram compreender o ambiente inovador da EaD, identificando e promovendo as características de uma gestão que melhor contribua com o desenvolvimento dessa modalidade, além de resumir muito bem o cenário de transformação na chegada do PAP no Município, quando trouxe vários "ganhos para a comunidade da região, pois provocou mudanças", listadas a seguir:

$>$ Em relação à questão da qualificação e requalificação de professores da rede de ensino na região do entorno do polo, que é um dos objetivos, tanto do Sistema Cederj quanto da UAB/Capes - "O público em geral é atendido, mas os professores que atuam na Educação Básica têm prioridade de formação". Segundo a coordenadora do polo, os indicadores da educação no município de Resende apontam que aproximadamente $100 \%$ dos professores da PMR obtiveram sua graduação e $100 \%$ dos professores graduados da PMR estão em fase de conclusão de sua pós-graduação. Além disso, a maioria absoluta desses professores cursou a graduação e/ou a pós-graduação no Polo Resende UAB/Cederj;

> A qualificação dos profissionais envolvidos com a educação do município de Resende tornou possível a melhoria na qualidade do Ensino Fundamental, fato 
constatado pela evolução dos índices de "Produção da Educação Fundamental", que em 2005 estava próximo de 68\% e, em 2012, obteve um salto de melhoria, chegando à taxa de $85 \%$.

Dentre os problemas de gestão na EaD apresentados durante a pesquisa, as questões que envolvem o tema da gestão de pessoas requerem mais atenção, em especial de manter um quadro permanente de funcionários técnico-administrativos no sistema. Uma possível solução para esse cenário está na elaboração de uma política pública em que o mantenedor seja da esfera municipal ou estadual, atenda as necessidades, identificadas no plano de gestão do PAP, que estará contemplando o porte das suas edificações e cursos ofertados no polo.

No PAP Resende, percebe-se que está sendo considerado o contexto de operação dos processos e dos projetos na viabilização da implementação de novos cursos na modalidade EaD, que segundo Malmegrin (2012b), "na medida em que certa demanda traz para os processos e para os projetos certa carga que deve ser atendida a partir da alocação de certa capacidade". Em outras palavras, o PAP RES está em conformidade com os diversos fatores estruturais essenciais de uma gestão de qualidade, comportando o recebimento de mais cursos, principalmente sem ter que investir em edificações e/ou ambientes. Porém será necessária a contratação de pessoal nos Sistemas UAB e Cederj: tutores presenciais e a distância para as novas disciplinas, conforme o projeto pedagógico de cada curso.

Dos elementos essenciais apresentados no decorrer do estudo, sem dúvida o mais complexo está em formar uma equipe qualificada. Nos Sistemas UAB e Cederj, os tutores não fazem parte de um quadro de colaboradores permanente e são figuras muito importantes no sistema de tutoria, pois são os mediadores entre os coordenadores das disciplinas, o material didático e o estudante. Então a renovação desse quadro é uma constante, conforme observado no estudo, pois a prática adotada pelas IPES está no vínculo pelas bolsas de estudo e de pesquisa por um período de duração limitado em no máximo quatro anos, conforme as orientações e diretrizes da Resolução CD/FNDE no 26.

Diante dos cenários apresentados, em especial sobre os problemas de gestão do PAP existentes, que seja pesquisada para futuras versões a questão de políticas públicas que possibilitem ao mantenedor constituir um quadro permanente de funcionários técnico-administrativo para o PAP, em conformidade com o plano de gestão de cada PAP. 
Por fim, dentre os requisitos essenciais a serem considerados para a capacitação dos coordenadores de PAP, conforme afirma a entrevistada, no contexto atual, em que a UAB, por mais que proporcione um ambiente de colaboração e suporte para o gestor do PAP, disponibilizando informações para formação das suas competências de gestão, por meio dos encontros presenciais e das ferramentas on line, em que os coordenadores são agentes na construção de uma teia virtual de conhecimentos sobre várias questões relevantes que envolvem a gestão da $\mathrm{EaD}$, ainda existe a necessidade, pela maioria dos integrantes que participam do ATUAB, de que seja ofertado, pelas IPES, o curso de mestrado de Gestão em EaD.

\section{Notas}

1 "É uma forma de pesquisa que aborda com profundidade um ou poucos objetos de pesquisa, por isso tem grande profundidade e pequena amplitude" (Zanella, 2012).

2 "Explora a realidade, buscando maior conhecimento, para depois planejar uma pesquisa descritiva" que "tem o objetivo de descrever com exatidão os fatos e fenômenos de determinada realidade." (Zanella, 2012).

${ }^{3}$ Caracteriza-se, "em princípio, pela não utilização de instrumental estatístico na análise dos dados. Esse tipo de análise tem por base conhecimentos teórico-empíricos que permitem atribuir-Ihe cientificidade" (Zanella, 2012).

4 "É um tipo de comunicação preparado com objetivos definidos e estratégias de trabalho entre um pesquisador e informante sobre determinados fenômenos, objetos ou pessoas" (Silva, 2007, cap. 1, p. 4).

5 "É um conjunto de perguntas pré-elaboradas de forma sistemática e sequencial que buscam suscitar dos informantes respostas acerca do universo ou amostra pesquisada" (Silva, 2007, cap. 1, p. 4).

6 "O termo "gestão" é sinônimo de "administração" e significa um conjunto de princípios, normas e funções que têm por objetivo ordenar os fatores de produção e controlar a sua produtividade e eficiência para obter determinado resultado" (Malmegrin, 2012a).

7 "Projeto é um conjunto de atividades (tarefas, ações, procedimentos) de execução única, necessárias e suficientes para obtenção de uma solução ou de um produto, em contextos diretivos, normativos, de recursos e de aprendizado específicos" (Malmegrin, 2012b).

8 "Os polos de apoio presencial são as unidades operacionais para o desenvolvimento descentralizado de atividades pedagógicas e administrativas relativas aos cursos e programas ofertados a distância pelas instituições públicas de ensino superior no âmbito 
do Sistema UAB. Mantidos por municípios ou governos de estado, os polos oferecem a infraestrutura física, tecnológica e pedagógica para que os alunos possam acompanhar os cursos a distância" (UAB/Capes, 2013).

9 "Processo pelo qual são criados e utilizados instrumentos para implementação (concepção, difusão e continuidade) de práticas que conduzem às mudanças necessárias ao processo de desenvolvimento das organizações prestadoras de serviços públicos" (Malmegrin, 2012b).

10 Termo utilizado para caracterizar o ensino realizado em parte de forma presencial (com presença física, numa sala de aula) e em parte de forma virtual ou a distância (com pouca presença física), por meio de tecnologias de comunicação. Fonte: http://www.educabrasil.com.br/eb/dic/dicionario.asp?id=331.

11 "Regulado pelo o Decreto no 5.800. Art. 40 O Ministério da Educação firmará acordos de cooperação técnica ou convênios com os entes federativos interessados em manter polos de apoio presencial do Sistema UAB, observado o disposto no art. 5. Art. $5^{\circ}$ A articulação entre os cursos e programas de educação superior a distância e os polos de apoio presencial será realizada mediante edital publicado pelo Ministério da Educação, que disporá sobre os requisitos, as condições de participação e os critérios de seleção para o Sistema UAB" (UAB/Capes, 2013).

12 "Delegar é transferir 'autoridade' (poder) com a correspondente parcela de 'responsabilidade' (intrínseca à relação) à outra pessoa para a execução de 'determinada' atividade" (Bergue, 2012a).

13 Eficiência - "Critério que considera a relação entre: os resultados obtidos e os insumos consumidos". Eficácia - "A relação está entre os resultados obtidos e os resultados planejados" (Malmegrin, 2012b).

14 "É a representação gráfica que mostra a composição formal do sistema organizacional em dado momento, evidenciando, além da macrodivisão do trabalho, as relações formais entre as áreas e os órgãos (subsistemas organizacionais) e os níveis hierárquicos institucionais" (Bergue, 2012a).

15 "Departamentalizar as organizações significa definir seus critérios mais amplos de divisão de trabalho. Essa divisão de trabalho tende a obedecer a determinados critérios já sedimentados pela prática administrativa" (Bergue, 2012a).

16 "O ATUAB é o ambiente de trabalho da Universidade Aberta do Brasil restrito aos seus colaboradores. Configura-se numa personalização do ambiente virtual de aprendizagem (AVA) para o compartilhamento de informação, comunicação entre a Capes, IES e polos, além da gestão e discussão de temas de interesse para o desenvolvimento do Sistema UAB. Usuários: Participam desse ambiente os coordenadores UAB, coordenadores de curso, coordenadores de polo de apoio presencial e colaboradores da Capes" (UAB/Capes, 2013). 
17 "O SisUAB é uma plataforma de suporte para a execução, acompanhamento e gestão de processos da Universidade Aberta do Brasil. Está preparado para o cadastramento e consulta de informações sobre instituições, polos, cursos, material didático, articulações, colaboradores e mantenedores" (UAB/Capes, 2013).

18 "A Coordenação de Aperfeiçoamento de Pessoal de Nível Superior (Capes) tem como atribuições a avaliação da pós-graduação stricto sensu, acesso e divulgação da produção científica, investimentos na formação de especialistas de alto nível e promoção da cooperação científica internacional". http://www.brasil.gov.br/sobre/educacao/pos-graduacao/capes.

19 Liderança - "Capacidade de fazer com que um grupo, ainda que sob circunstâncias adversas, responda positivamente à indicação de um rumo de ação, por reconhecê-la como viável e necessária. Liderar, portanto, é influenciar legitimamente pessoas" (Bergue, 2012a).

\section{Referências bibliográficas}

Bergue, S. T. (2012). Comportamento organizacional. 2a ed. reimp. Florianópolis: UFSC / Departamento de Ciências da Administração.

Bergue, S. T. (2012). Cultura e mudança organizacional. 2a ed. reimp. Florianópolis: UFSC / Departamento de Ciências da Administração.

Brasil. Lei n 9.394, de 20 de dezembro de 1996. Lei de Diretrizes e Bases da Educação Nacional. Diário Oficial da União, Brasília, 24 dez. 1996. Disponível em: http://portal.mec.gov.br/seed/arquivos/pdf/tvescola/leis/lein9394.pdf. Acesso em jun. 2013.

FNDE - Fundo Nacional de Desenvolvimento da Educação. Resolução CD/FNDE no 26, de 5 de junho de 2009. Disponível em: http://www.fnde.gov.br/fnde/legislacao/resolucoes/item/3320resolu \%C3\%A7\%C3\%A3o-cd-fnde-n\%C2\%BA-26-de-5-de-junho-de-2009. Acesso em 27 jun. 2013.

Fundação Cecierj - Consórcio CEDERJ. Disponível em: http://www.cederj.edu.br/fundacao/. Acesso em mar. 2013.

Garbin, T., \& Dainese, C. A. (2010). Complexidade da Gestão em EaD - UFOP. Ouro Preto. Disponível em:_http://www.abed.org.br/congresso2010/cd/ 352010000655.pdf. Acesso em mar. 2013. 
Inep. (2013). Censo da Educação Superior 2011 Resumo Técnico. Disponível em: http://portal.inep.gov.br/web/censo-da-educacao-superior/resumos-tecnicos. Acesso em set. 2013.

Malmegrin, M. L. (2012). Introdução à gestão de redes públicas de cooperação em ambientes federativos. $2^{\mathrm{a}}$ ed. reimp. Florianópolis: UFSC / Departamento de Ciências da Administração; Brasília: CAPES/UAB.

Malmegrin, M. L. (2012). Gestão operacional. 2a ed. reimp. Florianópolis: UFSC / Departamento de Ciências da Administração; Brasília: CAPES/UAB.

Ministério da Educação. (2007). Secretaria de Educação a Distância. Referenciais de qualidade para a Educação Superior a Distância. Disponível em: http://portal.mec.gov.br/seed/arquivos/pdf/legislacao/refead1.pdf. Acesso em jun. 2013.

Mill, D., Brito, N. D., Silva, A. R., \& Almeida, L. F. (2010). Gestão da educação a distância (EaD): Noções sobre planejamento, organização, direção e controle da EaD. Disponível em: http://www.ufsj.edu.br/portal2repositorio/File/vertentes/Vertentes 35/daniel mill e outros.pdf. Acesso em mar. 2013.

Paula, K. C., Ferneda, E., \& Campos Filho, M. P. (2004). Elementos para implantação de cursos a distância. Colabor@ - Revista Digital da CVA, Ricesu. Disponível em: http://www.ricesu.com.br/colabora/n7/artigos/n 7/pdf/id 02.pdf. Acesso em mar. 2013.

Ribas, J. C. C., Moreira, B. C. M., \& Catapan, A. H. (2011). Construindo referenciais de qualidade para uma gestão eficaz no Sistema Universidade Aberta do Brasil: o ambiente virtual de ensino-aprendizagem e a capacitação dos coordenadores de polo de apoio presencial. Disponível em: http://www.abed.org.br/congresso2011/cd/35.pdf. Acesso em mar. 2013.

Santos, M. P. G. dos. (2012). O Estado e os problemas contemporâneos. 2a ed. Florianópolis: UFSC / Departamento de Ciências da Administração.

UAB/Capes - Universidade Aberta do Brasil. Disponível em: www.uab.capes.gov.br. Acesso em mar. 2013.

Zanella, L. C. H. (2012). Metodologia de estudo de pesquisa em administração. 2a ed. Florianópolis: UFSC / Departamento de Ciências da Administração. 